\title{
Approximately two thirds of adolescents with newly diagnosed eating disorders recovered within $5-11.5$ years
}

\author{
Steinhausen HC, Seidel R, Winkler Metzke C. Evaluation of treatment and intermediate and long-term outcome of \\ adolescent eating disorders. Psychol Med 2000 Sep;30:1089-98.
}

\section{QUESTIONS: In adolescents with newly diagnosed eating disorders, how long does treatment last, and what is the course of the disorder?}

\section{Design}

Inception cohort with mean follow up periods of 5 and 11.5 years.

\section{Setting}

A university department of child and adolescent psychiatry in Berlin, Germany.

\section{Patients}

60 adolescents (95\% girls) who had newly diagnosed eating disorders (anorexia nervosa [AN], restrictive type [80\%]; AN, bulimic type [10\%]; bulimia nervosa [8.3\%]; and atypical AN, bulimic type [1.7\%]) and had received inpatient treatment. The mean age of patients was 14.6 years at disease onset, 15.7 years at first admission, 20.9 years at first follow up, and 27.3 years at second follow up. $83 \%$ of patients were assessed at the first follow up and $77 \%$ at the second follow up.

\section{Assessment of prognostic factors}

Predictors of treatment duration and outcome were assessed, but $<80 \%$ of patients were included in this analysis.

\section{Main outcome measures}

Treatment duration; body mass index (BMI); eating disorder diagnosis; and symptoms (5 eating disorder and 6 sexuality and psychosocial items rated on a 4 point scale [absent, slight, moderate, severe]).

\section{Main results}

4 patients died during the first follow up period, and 1 patient died during the second follow up period (total mortality rate $8.3 \%$ ). Causes of death were complications of severe and chronic eating disorders $(n=4)$ or suicide $(n=1)$. The mean duration of inpatient treatment in the follow up period was 143 and 185 days for first and second follow up, respectively; for outpatient treatment, the mean duration was 14 and 17 months. Patients were in treatment for a mean $33 \%$ of the first 5 years. The mean BMI increased from $14.2 \mathrm{~kg} / \mathrm{m}^{2}$ at first admission to 19.3 $\mathrm{kg} / \mathrm{m}^{2}$ at first follow up (mean increase $5.1 \mathrm{~kg} / \mathrm{m}^{2}, 95 \%$ CI 4.2 to 6.0 ) and $19.6 \mathrm{~kg} / \mathrm{m}^{2}$ at second follow up. The proportions of patients with eating disorders were $10 \%$ and $5 \%$ for $\mathrm{AN}$, restrictive type; $4 \%$ and $2 \%$ for $\mathrm{AN}$, bulimic type; $0 \%$ and $5 \%$ for bulimia nervosa; and 14\% and $9 \%$ for atypical $\mathrm{AN}$ at first and second follow up, respectively. $68 \%$ of patients at first follow up and $78 \%$ of patients who were interviewed at second follow up had no eating disorder. The proportions of patients with moderate or severe symptom ratings on symptom scales for first and second follow up were $38 \%$ and $22 \%$ for avoidance of sexual behaviour, $27 \%$ and $7 \%$ for amenorrhea, $20 \%$ and $4 \%$ for avoidance of sexual matters, $18 \%$ and $13 \%$ for unsatisfactory family relationships, $18 \%$ and $11 \%$ for anorexic eating behaviour, $12 \%$ and $9 \%$ for vomiting, $12 \%$ and $4 \%$ for unsatisfactory social contacts, $10 \%$ and $11 \%$ for impaired vocational career, $8 \%$ and $7 \%$ for bulimia, $6 \%$ and $2 \%$ for laxative abuse, and $6 \%$ and $7 \%$ for dependency upon the family.

\section{Conclusions}

Adolescents with newly diagnosed eating disorders were in treatment for approximately one third of the first 5 years after initial hospital discharge. Approximately two thirds of patients recovered after 5-11.5 years. The mean body mass index increased by approximately 5 $\mathrm{kg} / \mathrm{m}^{2}$, but $8 \%$ of patients died.

\section{COMMENTARY}

The long term cohort study by Steinhausen $e t$ al adds to a growing number of reports showing the variable long term outcome of adolescent eating disorders and the difficulty of predicting outcome in an individual case.

There are important service delivery implications here. Because this sample had been in hospital for an average of 3 months at the outset, it is clear that this did not usually result in a complete cure. Weight restoration in hospital has previously been shown to be a poor marker of progress, particularly when enforced. ${ }^{1}$ Whether initial hospital admission acts as a help or hindrance to long term outcome is unknown.

Many patients required expensive treatment spanning many years, often into adulthood. This matches the experience in other Western countries. Therefore, well functioning liaison in the interface between child and adult services is crucial.

The outcome of normal weight bulimia nervosa is less clear. Results from the mixed diagnostic group are reported here, which makes comparison of the outcome and mortality rates with other series difficult and the interpretation of such outcomes as mean weight gain confusing. The reported mortality rate is in the middle range; other reported rates range from $0-22 \%{ }^{2}$

On a positive note, most patients eventually recovered fully. This finding is in keeping with that of Theander who found recovery occurred up to 12 years after first presentation but not beyond. ${ }^{3}$ Although anorexia nervosa has often been considered to be a remitting and relapsing disorder, the interesting survival analysis graphs indicate that when full recovery occurs, it is usually lasting.

Professor Simon Gowers, FRCPsych, MPhil Royal Liverpool University Hospital Liverpool, UK

1 Gowers SG, Weetman J, Shore A, et al. Impact of hospitalisation on the outcome of adolescent anorexia nervosa. $\mathrm{BrJ}$ Psychiatry 2000;176:138-41.

2 Niederman M. Progonosis and outcome. In: Lask B, BryantWaugh R, editors. Anorexia nervosa and related eating disorders in childhood and adolescence. 2nd edition. Hove: Psychology Press, 2000:81-101.

3 Theander S. Outcome and prognosis in anorexia nervosa and bulimia: some results of previous investigations, compared with those of a Swedish long-term study.J Psych atr Res 1985;19:493-508.
Source of funding: no external funding.

For correspondence: Professor $H C$

Steinhausen,

Department of Child and Adolescent

Psychiatry, University of Zürich,

Neumünsterallee, Postfach, $\mathrm{CH}-8032$ Zürich, Switzerland Fax +4114221873. steinh@kjpd.unizh.ch 